Cahiers $d u$ MONDE RUSSE

\section{Cahiers du monde russe}

Russie - Empire russe - Union soviétique et États indépendants

$58 / 4 \mid 2017$

Varia

\title{
Elitza Dulguerova, Usages et utopies : L'exposition dans l'avant-garde russe prérévolutionnaire (1900-1916)
}

\section{Cécile Pichon-Bonin}

\section{(2) OpenEdition}

1 Journals

\section{Édition électronique}

URL : http://journals.openedition.org/monderusse/10201

DOI : 10.4000/monderusse. 10201

ISSN : $1777-5388$

Éditeur

Éditions de l'EHESS

\section{Édition imprimée}

Date de publication : 1 octobre 2017

Pagination : 760-762

ISBN : 978-2-7132-2698-4

ISSN : $1252-6576$

\section{Référence électronique}

Cécile Pichon-Bonin, «Elitza Dulguerova, Usages et utopies : L'exposition dans l'avant-garde russe prérévolutionnaire (1900-1916) », Cahiers du monde russe [En ligne], 58/4 | 2017, mis en ligne le 01 octobre 2017, consulté le 06 janvier 2021. URL : http://journals.openedition.org/monderusse/10201 DOI : https://doi.org/10.4000/monderusse.10201 


\section{Elitza DULGUEROVA}

\section{Usages et utopies}

\section{L'exposition dans l'avant-garde russe prérévolutionnaire (1900-1916)}

Dijon : Les Presses du réel (Euvres en sociétés), 2015, 584 p.

Dans son ouvrage, Elitza Dulguerova fonde sa réflexion sur huit expositions clés de l'avant-garde russe, mises en œuvre à Moscou et à Petrograd entre 1900 et 1916, et qui ont en commun leur caractère d'exposition collective. À travers l'analyse de ces événements, il s'agit de comprendre pourquoi et comment les conditions de présentation (physiques, temporelles et publiques) sont devenues une donnée indissociable de la production de sens et d'effet des œuvres mêmes. L'auteur émet l'hypothèse que ces expositions de groupe sont non seulement une adaptation à une nouvelle conjoncture sociale et économique du monde de l'art, mais qu'elles rencontrent aussi les utopies de la création des artistes d'avant-garde.

Usages et utopies, pour reprendre le titre de l'ouvrage, dialoguent ainsi tout au long de la réflexion autour de trois thèmes transversaux. Le premier concerne les pratiques expositionnelles (en tant que reflets des contraintes sociales dans une conjoncture historique donnée, avec leurs normes, leurs codes, leurs conventions) et leur dépassement ou leur détournement par les artistes. Le deuxième porte sur la relation des expositions, des œuvres et des artistes à l'espace public. L'auteur investit un domaine peu exploré jusqu'alors en étudiant la répercussion, sur les démarches des plasticiens, de la sécularisation et de la démocratisation des pratiques artistiques, en expansion depuis le XVIII ${ }^{\mathrm{e}}$ siècle, et qui ont rendu l'art perméable aux contraintes du marché et dépendant des institutions de l'État-Nation, poussant toujours plus les artistes vers l'espace public, à la recherche de leur raison d'être. En envisageant notamment l'espace public comme 
un élément constitutif des pratiques artistiques, Elitza Dulguerova éclaire de façon nouvelle l'articulation entre les quêtes d'une fonction sociale et de l'autonomie de l'art. Le troisième thème, enfin, se rapporte à une réflexion sur le rapport entre la temporalité des expositions de groupe, leur ancrage dans un présent et le fait que ces événements créent de l'histoire.

Le livre se divise en trois parties, traitant chacune de la situation à des périodes données : avant 1910, 1911-1914 et 1915-1916. Il comprend aussi une cinquantaine de pages d'annexes proposant des traductions de textes sources venant compléter l'analyse et donner un aperçu des débats que l'exposition a suscité dans la Russie prérévolutionnaire. La première partie de l'ouvrage pose les bases de la réflexion grâce à une présentation des formes de l'exposition en Russie et des discours qui lui ont été consacrés. Il y est notamment question de la Rose bleue et du Monde de l'art. Les deux parties suivantes présentent une succession d'études de cas problématisées et consacrées chacune à une exposition emblématique de l'avant-garde russe. Sont ainsi passées en revue Le Valet de carreau, La Queue d'âne, La Cible, $N^{\circ} 4$ qui doivent beaucoup à l'activité de Mihajl Larionov, puis les expositions Tramway $V$, L'année 1915, 0-10 et Magasin, dans lesquelles se sont impliqués Kazimir Malevič et Vladimir Tatlin.

L'auteur suit une méthode rigoureuse d'analyse de chaque exposition, interrogeant l'identité des organisateurs et des participants, le lieu, les dates et la durée de l'événement, les œuvres exposées, leur accrochage, l'intitulé des manifestations, le catalogue, les publications et/ou conférences proposées autour de l'exposition, la réception médiatique, la conjoncture artistique, politique et sociale tout autant que l'inscription de l'événement dans une histoire longue.

Les sources primaires rassemblées à cet effet sont diverses, visuelles aussi bien que textuelles, grâce notamment à un scrupuleux dépouillement de la presse et à une collecte large des textes théoriques. L'auteur propose un point de vue novateur sur ces sources et analyse par exemple avec finesse les usages de la photographie d'œuvres et d'expositions dans la presse et la relation de certains artistes aux médias de masse.

Outre la méthode d'analyse développée et le traitement des sources que nous venons d'évoquer, l'ouvrage d'Elitza Dulguerova possède encore deux atouts majeurs. Il constitue tout d'abord un apport évident à l'histoire des expositions, et ce à plusieurs égards. En inscrivant l'exposition collective dans une histoire longue, il permet de mieux saisir la genèse, les types, les usages et les fonctions (esthétiques, socio-économiques et politiques) de ces manifestations. En faisant le choix de constituer ces huit expositions en série, l'auteure invite aussi à « décanoniser» (p. 39) la célèbre exposition 0-10 pour repenser les jalons traditionnels de l'histoire de l'art russe d'avant-garde ainsi que les ruptures, nouveautés et continuités existantes entre ces événements, généralement abordés séparément comme des moments singuliers. Par sa méthode, croisant histoire sociale de l'art, histoire des idées et des représentations, Elitza Dulguerova se fonde sur la présentation factuelle des événements, ce qui constitue déjà en soi une synthèse informative appréciable, pour atteindre son objectif d'étudier les façons dont l'exposition produit du sens. 
C'est aussi grâce à cette approche interdisciplinaire que ce livre participe à une meilleure compréhension des œuvres et des démarches artistiques de l'avant-garde russe. C'est là le dernier atout que nous soulignerons, sans prétendre avoir épuisé les mérites de l'ouvrage. L'exploration de la relation entre les œuvres et leurs modes d'exposition, conduite notamment grâce à un élargissement du concept de «parergon » employé par Jacques Derrida, permet de développer l'analyse des œuvres et des mouvements artistiques tout autant que des principales problématiques de l'histoire de l'art russe et occidental des $\mathrm{XIX}^{\mathrm{e}}$ et $\mathrm{XX}^{\mathrm{e}}$ siècles.

Le lecteur pourra, par exemple, porter un nouveau regard sur le débat symboliste traitant de l'opposition entre individualisme et communion et découvrir les manières dont l'avant-garde a tenté d'apporter des réponses aux questions soulevées par ces discussions, à travers la mise en œuvre des expositions de groupe. L'entrée dans l'histoire de l'art russe par l'analyse des expositions collectives apporte ainsi un nouvel éclairage à de grands thèmes de cette histoire en particulier et de l'histoire de l'art en général, parmi lesquels : le rapport des artistes à un public plus large, la perception des œuvres par ce public diversifié, les relations entre les plasticiens et l'établissement d'une hiérarchie au sein des expositions et de la profession, l'articulation entre œuvre d'art et marchandise ou l'évolution du statut de l'artiste (tel que défini par Nathalie Heinich pour englober à la fois la dimension réelle des conditions matérielles d'exercice de l'activité et la dimension imaginaire des représentations qui y sont associées). Les scandales, traditionnellement considérés comme provoqués par les œuvres elles-mêmes, trouvent ici de nouvelles causes et deviennent la conséquence des modes de présentation des créations et des stratégies médiatiques développées notamment par Mihail Larionov. Enfin, certaines caractéristiques iconographiques et formelles, comme le thème de la lutte ou la place et le rôle des références aux arts populaires dans la peinture néoprimitiviste, gagnent aussi à être pensées au sein de l'exposition et voient ainsi leur compréhension approfondie et investie d'une nouvelle dimension.

\section{Cécile Pichon-Bonin}

Chargée de recherche au CNRS, Centre Georges Chevrier 